Research Article

\title{
Clinical Characteristics of Patients with Newly Diagnosed Diabetic Macular Edema in Turkey: A Real-Life Registry Study-TURK-DEM
}

\author{
Bora Eldem, ${ }^{1}$ Sengul Ozdek, ${ }^{2}$ Ali Osman Saatci, ${ }^{3}$ Emin Ozmert, ${ }^{4}$ Esat Ulay, ${ }^{5}$ and \\ Gulsah Nomak ${ }^{5}$ \\ ${ }^{1}$ Department of Ophthalmology, Hacettepe University Faculty of Medicine, Ankara, Turkey \\ ${ }^{2}$ Department of Ophthalmology, Gazi University Faculty of Medicine, Ankara, Turkey \\ ${ }^{3}$ Department of Ophthalmology, Dokuz Eylul University Faculty of Medicine, Izmir, Turkey \\ ${ }^{4}$ Department of Ophthalmology, Ankara University Faculty of Medicine, Ankara, Turkey \\ ${ }^{5}$ Bayer Türk, Istanbul, Turkey
}

Correspondence should be addressed to Bora Eldem; beldem@superonline.com

Received 3 October 2016; Accepted 19 January 2017; Published 19 February 2017

Academic Editor: Lisa Toto

Copyright (c) 2017 Bora Eldem et al. This is an open access article distributed under the Creative Commons Attribution License, which permits unrestricted use, distribution, and reproduction in any medium, provided the original work is properly cited.

Purpose. To evaluate the clinical and diagnostic characteristics of patients with newly diagnosed diabetic macular edema (DME) in Turkey in a real-life setting. Methods. A total of 945 consecutive patients (mean (SD) age: 61.3 (9.9) years, 55.2\% male) with newly diagnosed DME were included. Data on patient demographics, comorbidities, ocular history, ophthalmic examination findings including type of DME, central macular thickness (CMT) via time domain (TD) and spectral domain (SD) optical coherence tomography (OCT), and planned treatments were recorded. Results. OCT (98.8\%) and fundoscopy (92.9\%) were the two most common diagnostic methods. Diffuse and focal DMEs were detected in 39.2\% and 36.9\% of cases, respectively. Laser photocoagulation (32.1\%) and antivascular endothelial growth factors (anti-VEGF; 31.8\%) were the most commonly planned treatments. The median CMT in the right eye was significantly greater in untreated than in treated patients [376.5 $\mu \mathrm{m}$ (range: $160-840$ ) versus $342 \mu \mathrm{m}$ (range: 146-999) $(p=0.002)$ ] and in the left eye [370 $\mu \mathrm{m}$ (range: 201-780) versus $329 \mu \mathrm{m}$ (range: $148-999)(p<0.001)]$. Conclusions. This study is the first large-scale real-life registry of DME patients in Turkey. SD-OCT and fundoscopy were the most common diagnostic methods. Laser photocoagulation and anti-VEGF therapy were the most common treatments.

\section{Introduction}

Diabetic macular edema (DME) is a major complication of diabetes mellitus that affects central vision. The symptoms of DME range from slight visual blurring to complete blindness if left untreated $[1,2]$. Recent estimates are that, by the year 2030, 350 million people worldwide will have diabetes [3] and 100 million of them will have DME [4].

The worldwide prevalence of DME was reported as $6.81 \%$ among patients with diabetes [5]. Other research reported that the 10-year incidence of DME was 14\% in individuals with type 2 diabetes, and progression to DME occurred in $29 \%$ of individuals with type 1 diabetes over 25 years if left untreated [6,7]. Although DME resolves spontaneously in about $33 \%$ to $35 \%$ of patients, it tends to be chronic in most patients $[3,8,9]$. DME accounts for the loss of 3 Snellen lines of vision in $24 \%$ of eyes within 3 years [8] and in $12 \%$ of all new cases of blindness annually [10]. The high prevalence and potential severity of DME point to the need for prompt and effective treatment $[11,12]$.

Limited data are available on characteristics of DME patients in Turkey, and most data are from clinical trials. Only one multicenter registry examined the frequency of diabetic retinopathy and risk factors in Turkey. This previous study reported that the overall prevalence of DME was 3.4\% in patients with newly diagnosed diabetes $(n=298), 9.7 \%$ in 
those with type 1 diabetes and $2.4 \%$ in those with type 2 diabetes [13].

Real-life studies have high generalizability because, in contrast to randomized controlled trials, they provide data on real-life situations rather than on a specific set of patients who were selected under strict and controlled conditions [14]. There is a need for a registry study to investigate the baseline characteristics of patients with DME in Turkey. The TURKDEM study is the first large-scale observational registry of DME patients in Turkey. The purpose is to evaluate the reallife demographic, clinical, and diagnostic characteristics of patients with newly diagnosed DME in Turkey.

\section{Material and Methods}

2.1. Study Population. A total of 945 consecutive patients (mean age \pm SD: $61.3 \pm 9.9$ years, $55.2 \%$ male) with newly diagnosed DME were included in this national, multicenter, cross-sectional, noninterventional, observational, and singlevisit study conducted at 36 retina centers across Turkey between March 2013 and July 2014. Study centers were well-equipped reference centers and were selected so that the study patients had geographical and other characteristics that were representative of Turkey in general.

All patients were at least 18 years old, had newly diagnosed DME, and received no previous DME-specific treatment. Patients who participated in a previous clinical study and those who already received or were currently receiving treatment for DME were excluded.

Each subject provided written informed consent for participation after being provided with a detailed explanation of the study objectives. The protocol of this study was approved by the institutional ethics committee and was conducted in accordance with the ethical principles stated in the "Declaration of Helsinki" and local regulations.

2.2. Data Collection. All patients were evaluated on a single visit, and data on demographics and medical history were recorded. This included history of diabetes (type, treatment, presence of systemic complications such as diabetic foot, time from onset to DME diagnosis, and follow-up care), hypertension and receipt of antihypertensive treatment, vital signs, body mass index $\left(\mathrm{kg} / \mathrm{m}^{2}\right)$, blood biochemistry, ocular history (reason for visiting an ophthalmologist, concomitant ocular diseases, and previous eye operations), ophthalmic examination findings including Early Diabetic Retinopathy Study (ETDRS), best-corrected visual acuity (BCVA), Snellen test score, type of DME (focal, diffuse, center-involving, clinically significant, and others), central macular thickness [CMT at the time of diagnosis via time domain (TD) and spectral domain (SD) optical coherence tomography (OCT)], and planned pharmacological treatments (corticosteroids, antivascular endothelial growth factor [anti-VEGF] agents) and nonpharmacological treatments (laser photocoagulation, vitrectomy).

2.3. Statistical Analysis. Sample size calculation was performed using NCSS PASS 11 ver. 11.0.7 (Utah, USA). The results indicated that at least 900 patients from 36 centers should be included to achieve a confidence level of more than $95 \%$ and a statistical power of $80 \%$, based on the patient enrollment capacity of the study centers (40 patients/year in high-capacity centers, 13 patients/year in low-capacity centers).

Statistical analysis was performed using SPSS (IBM Corp. 2012, IBM SPSS Statistics for Windows, version 21.0., Armonk, NY). When the data had nonnormal distributions, the Mann-Whitney $U$ test was used to compare paired independent groups and the Kruskal-Wallis test was used for multiple comparisons of independent groups. In subgroup comparisons, when a nonnormal distribution was present, the Mann-Whitney $U$ test, chi-square test, and Fisher's exact test were performed with the Bonferroni correction. For categorical variables, when the conditions for a chi-square test were present, the chi-square test was used to analyze paired and multiple groups. When the conditions for a chi-square condition were not present, Monte Carlo simulation was used for multiple group comparisons. All data are expressed as means and standard deviations (SDs), medians and minimum-maximum values, or percentages where appropriate. A $p$ value less than 0.05 was considered statistically significant.

\section{Results}

3.1. Baseline Characteristics. We enrolled 945 consecutive patients [mean (SD) age: 61.3 (9.9) years, 55.2\% male], $96.4 \%$ with type 2 diabetes and $3.6 \%$ with type 1 diabetes (Table 1 ). The time from onset of diabetes to diagnosis of DME was $10-14$ years in $29.5 \%$ of patients and was less than 5 years in $12.0 \%$ of patients. Most patients were receiving treatment for diabetes $(65.5 \%)$, and most were followed by internal medicine clinics (47\%). Data on blood biochemistry were available for 263 patients $(27.8 \%)$. These data indicate that the mean (SD) fasting blood glucose level was $187.8(81.9) \mathrm{mg} / \mathrm{dL}$ and HbAlc level was 8.8 (2.3) \%.

3.2. Ocular History. Most patients visited an ophthalmologist due to vision problems (52.2\%) rather than due to referral (Table 2). The most common concomitant eye disease was cataract (29.9\%). Overall, 162 patients $(17.1 \%)$ had previous ocular operations and there were 210 total eye operations (due to multiple procedures in some patients). Cataract surgery was the most common eye operation $(n=210,92.4 \%)$.

3.3. Ophthalmic Findings. During the study visit, fundoscopy was performed in 878 patients $(92.9 \%)$ and fundus fluorescein angiography in 690 patients $(73.0 \%)$ (Table 3). OCT was performed in 935 patients $(98.8 \%)$; SD-OCT was performed in 838 patients $(89.6 \%)$ and TD-OCT in 97 patients (10.4\%). Overall, 11 patients were only assessed using a slitlamp with a $+78 \mathrm{D}$ lens for diagnosis of DME.

Intraocular pressure was measured in 655 patients (69.3\%); this was determined by a pneumatic method in 459 patients $(70.1 \%)$ and an applanation method in 196 patients $(29.9 \%)$. The mean (SD) intraocular pressure was 15.5 (3.3) $\mathrm{mmHg}$ in the right eye and 15.7 (3.8) $\mathrm{mmHg}$ in the left eye (Table 3 ). 
TABLE 1: Baseline characteristics of patients from Turkey with newly diagnosed diabetic macular edema.

\begin{tabular}{|c|c|}
\hline Age, mean (SD; min-max) & $61.3(9.9 ; 20-88)$ \\
\hline \multicolumn{2}{|l|}{ Sex, $n(\%)$} \\
\hline Male & $522(55.2)$ \\
\hline Female & $423(44.8)$ \\
\hline Body mass index $\left(\mathrm{kg} / \mathrm{m}^{2}\right)$, mean (SD) & $28.9(5.4)$ \\
\hline Systolic blood pressure ( $\mathrm{mmHg}$ ), mean (SD) & $132.3(15.6)$ \\
\hline Diastolic blood pressure (mmHg), mean (SD) & $83.5(11.6)$ \\
\hline \multicolumn{2}{|l|}{ Hypertension } \\
\hline Present & $521(55.1)$ \\
\hline Undertreatment $^{\mathrm{a}}$ & $404(77.5)$ \\
\hline On dialysis & $13(5.7)$ \\
\hline \multicolumn{2}{|l|}{ Diabetes } \\
\hline Type 1 & $34(3.6)$ \\
\hline Type 2 & $911(96.4)$ \\
\hline Undertreatment $^{\mathrm{b}}$ & $619(65.5)$ \\
\hline Diabetic foot disease & $44(4.7)$ \\
\hline \multicolumn{2}{|l|}{$\begin{array}{l}\text { Time from onset of diabetes to DME diagnosis, } \\
n(\%)\end{array}$} \\
\hline Less than 5 years & $113(12.0)$ \\
\hline $5-9$ years & $200(21.2)$ \\
\hline $10-14$ years & $279(29.5)$ \\
\hline $15-19$ years & $193(20.4)$ \\
\hline 20 years + & $160(16.9)$ \\
\hline \multicolumn{2}{|l|}{$\begin{array}{l}\text { Disciplines involved in diabetes follow-up care, } \\
n(\%)\end{array}$} \\
\hline None (not followed up) & $165(17.5)$ \\
\hline Endocrinology & $267(28.3)$ \\
\hline Internal medicine & $444(47.0)$ \\
\hline Family practice & $65(6.9)$ \\
\hline Nephrology & $4(0.4)$ \\
\hline \multicolumn{2}{|l|}{ Blood biochemistry $(n=263)$} \\
\hline \multicolumn{2}{|l|}{ Fasting blood glucose (mg/dL) } \\
\hline$N$ & 206 \\
\hline Mean (SD) & $187.8(81.9)$ \\
\hline \multicolumn{2}{|l|}{ HbAlc (\%) } \\
\hline$N$ & 165 \\
\hline Mean (SD) & $8.8(2.3)$ \\
\hline \multicolumn{2}{|l|}{ Total cholesterol (mg/dL) } \\
\hline$N$ & 99 \\
\hline Mean (SD) & $203.7(61.2)$ \\
\hline \multicolumn{2}{|l|}{$\mathrm{LDL}(\mathrm{mg} / \mathrm{dL})$} \\
\hline$N$ & 114 \\
\hline Mean (SD) & $124.5(42.0)$ \\
\hline \multicolumn{2}{|l|}{ HDL (mg/dL) } \\
\hline$N$ & 98 \\
\hline Mean (SD) & $47.7(21.3)$ \\
\hline \multicolumn{2}{|l|}{ Triglyceride (mg/dL) } \\
\hline$N$ & 113 \\
\hline Median (min-max) & $142(43-880)$ \\
\hline
\end{tabular}

TABle 1: Continued.

\begin{tabular}{lc}
\hline Urea $(\mathrm{mg} / \mathrm{dL})$ & \\
$N$ & 127 \\
Median $(\mathrm{min}-\mathrm{max})$ & $28.8(4.4-178)$ \\
Creatinine $(\mathrm{mg} / \mathrm{dL})$ & 140 \\
$N$ & $0.9(0.4-7.0)$ \\
$\quad$ Median $(\min -\mathrm{max})$ & \\
Microalbuminuria $(\mathrm{mg} / \mathrm{dL})$ & 36 \\
$\quad N$ & $25(0-741)$ \\
$\quad$ Median $(\min -\max )$ & \\
\hline Missing data for ${ }^{\mathrm{a}} 27$ and $^{\mathrm{b}} 130$ patients. &
\end{tabular}

TABle 2: Ocular history of patients from Turkey with newly diagnosed diabetic macular edema.

\begin{tabular}{lc}
\hline Reason for visiting ophthalmologist & $n(\%)$ \\
Routine control & $360(38.1)$ \\
Vision problem & $493(52.2)$ \\
Consultation & $92(9.7)$ \\
Referred from (for routine control or consultation) & \\
No referral & $672(71.1)$ \\
Endocrinology & $108(11.4)$ \\
Internal medicine & $107(11.3)$ \\
Family medicine & $5(0.5)$ \\
Other & $53(5.6)$ \\
Concomitant eye diseases, $n(\%)$ & \\
Cataract & $283(29.9)$ \\
Glaucoma & $36(3.8)$ \\
Other & $626(66.2)$ \\
Previous eye operations, $n(\%)$ & $162(17.1)$ \\
Total eye operations & 210 \\
Cataract surgery & $194(92.4)$ \\
Vitrectomy & $4(1.9)$ \\
Fellow eye operations & $12(5.7)$ \\
\hline
\end{tabular}

The BCVA was measured using an ETDRS chart in 36 right eyes and in 35 left eyes and using a Snellen chart in 771 right eyes and in 769 left eyes. The mean (SD) ETDRSBCVA was 63.3 (58.5) logMAR for the right eye and 68.4 (58.1) $\log$ MAR for the left eye in 36 patients. The mean (SD) Snellen score was $0.5(0.3)$ for both eyes in 771 and in 769 patients (Table 3 ).

Overall, 1888 eyes were examined. Diffuse DME was diagnosed in $39.2 \%$ of eyes and focal DME in $36.9 \%$ of eyes. At the time of diagnosis, the mean (SD) CMT was $381.1 \pm 140.4 \mu \mathrm{m}$ for both eyes $(n=1183)$ and a CMT greater than $300 \mu \mathrm{m}$ was present in $66.6 \%$ of eyes. At diagnosis, the mean (SD) CMT of the right and left eyes was 384.6 (144.0) $\mu \mathrm{m}$ and 377.7 (136.6) $\mu \mathrm{m}$, respectively. The mean (SD) CMT of the right and left eyes was 341.6 (129) $\mu \mathrm{m}$ and $342.0(124.7) \mu \mathrm{m}$ based on TD-OCT and 389.3 (145.2) $\mu \mathrm{m}$ and 381.5 (137.6) $\mu \mathrm{m}$ based on SD-OCT (Table 3). 
TABLE 3: Ophthalmic examination findings of patients.

\begin{tabular}{|c|c|c|c|c|}
\hline & Right eye & & Left eye & \\
\hline \multicolumn{5}{|l|}{ ETDRS best-corrected visual acuity score } \\
\hline$N$ & 36 & & 35 & \\
\hline Mean (SD) & $63.3(58.5)$ & & $68.4(58.1)$ & \\
\hline Median (min-max) & $56.5(0-310)$ & & $55(0-280)$ & \\
\hline \multicolumn{5}{|l|}{ Snellen test score } \\
\hline$N$ & 771 & & 769 & \\
\hline Mean (SD) & $0.5(0.3)$ & & $0.5(0.3)$ & \\
\hline Median (min-max) & $0.5(0.05-1)$ & & $0.5(0.05-1)$ & \\
\hline \multicolumn{5}{|l|}{$n(\%)$} \\
\hline $1.0 \log$ MAR $(20 / 200)$ & $97(12.6)$ & & $92(12)$ & \\
\hline $0.9 \log$ MAR $(20 / 158)$ & $43(5.6)$ & & $44(5.7)$ & \\
\hline $0.8 \log$ MAR $(20 / 126)$ & $58(7.5)$ & & $69(9)$ & \\
\hline $0.7 \log M A R(20 / 100)$ & $69(8.9)$ & & $61(7.9)$ & \\
\hline $0.6 \log \mathrm{MAR}(20 / 79)$ & $61(7.9)$ & & $58(7.5)$ & \\
\hline $0.5 \log \mathrm{MAR}(20 / 63)$ & $76(9.9)$ & & $73(9.5)$ & \\
\hline $0.4 \log \mathrm{MAR}(20 / 50)$ & $59(7.7)$ & & $71(9.2)$ & \\
\hline $0.3 \log \mathrm{MAR}(20 / 39)$ & $67(8.7)$ & & $75(9.8)$ & \\
\hline $0.2 \log \mathrm{MAR}(20 / 31)$ & $81(10.5)$ & & $78(10.1)$ & \\
\hline $0.1 \log M A R(20 / 25)$ & $75(9.7)$ & & $61(7.9)$ & \\
\hline$<0.1 \log$ MAR $(20 / 22)$ & $85(11)$ & & $87(11.3)$ & \\
\hline Intraocular pressure (mmHg), mean (SD) & $15.5(3.3)$ & & $15.7(3.8)$ & \\
\hline DME type, $n(\%)$ & Right eye & Left eye & & Both eyes \\
\hline Diffuse & $403(42.7)$ & $337(35.7)$ & & $740(39.2)$ \\
\hline Focal & $325(34.4)$ & $371(39.3)$ & & $696(36.9)$ \\
\hline Mix & $93(9.9)$ & $89(9.4)$ & & $182(9.6)$ \\
\hline Not defined & $120(12.7)$ & $130(13.8)$ & & $250(13.2)$ \\
\hline Invisible fundus & $3(0.3)$ & $17(1.8)$ & & $20(1.1)$ \\
\hline Total $^{\mathrm{a}}$ & $944(100.0)$ & $944(100.0)$ & & $1888(100.0)$ \\
\hline Central macular thickness $(\mu \mathrm{m})^{\mathrm{b}}$ & Right eye & Left eye & & Both eyes \\
\hline \multicolumn{5}{|l|}{ At the time of diagnosis } \\
\hline$N$ & 912 & 901 & & 1813 \\
\hline Mean (SD) & $384.6(144.0)$ & 377.7 (136.6) & & $381.1(140.4)$ \\
\hline \multicolumn{5}{|l|}{ Time domain OCT } \\
\hline$N$ & 96 & 92 & & - \\
\hline Mean (SD) & $341.6(129.0)$ & $342.0(124.7)$ & & - \\
\hline \multicolumn{5}{|l|}{ Spectral domain OCT } \\
\hline$N$ & 812 & 805 & & - \\
\hline Mean (SD) & $389.3(145.2)$ & $381.5(137.6)$ & & - \\
\hline \multicolumn{5}{|l|}{$n(\%)$} \\
\hline$\leq 300 \mu \mathrm{m}$ & $298(32.7)$ & $308(34.2)$ & & $606(33.4)$ \\
\hline$>300 \mu \mathrm{m}$ & $614(67.3)$ & $593(65.8)$ & & 1207 (66.6) \\
\hline Total & $912(100.0)$ & $901(100.0)$ & & $1813(100.0)$ \\
\hline
\end{tabular}

${ }^{\mathrm{a}}$ Due to the lack of data in 1 patient, analyses were for 1888 eyes in 944 patients.

${ }^{\mathrm{b}}$ Due to the noninterventional design, data were available only for patients who had the test.

3.4. Treatment Preferences. Laser photocoagulation therapy $(32.1 \%)$ and anti-VEGF therapy (31.8\%) were the most commonly preferred planned treatments, followed by anti-VEGF + laser photocoagulation therapy (30.8\%) (Table 4).
3.5. Clinical Characteristics of Patients with or without Antidiabetic Treatment. Patients who received antidiabetic treatment were significantly more likely to have type 1 diabetes $(p=0.005)$, to have a longer duration of diabetes $(p<0.001)$, to be active smokers $(p<0.001)$, and to 
TABLE 4: Planned treatments for the patients.

\begin{tabular}{lccc}
\hline Treatment, $n(\%)$ & Right eye & Left eye & Total \\
\hline Anti-VEGF + laser & $264(36.8)$ & $174(24.6)$ & $438(30.8)$ \\
Anti-VEGF & $240(33.5)$ & $213(30.1)$ & $453(31.8)$ \\
Laser & $178(24.8)$ & $279(39.5)$ & $457(32.1)$ \\
Steroid + laser & $13(1.8)$ & $10(1.4)$ & $23(1.6)$ \\
Steroid & $4(0.6)$ & $6(0.8)$ & $9(0.6)$ \\
Vitrectomy & $3(0.4)$ & $3(0.4)$ & $7(0.5)$ \\
Steroid + anti-VEGF & $1(0.1)$ & $1(0.1)$ & $2(0.1)$ \\
Other & $14(2.0)$ & $21(3.0)$ & $35(2.5)$ \\
Total & $717(100.0)$ & $707(100.0)$ & $1424(100.0)$ \\
\hline
\end{tabular}

have hypertension $(p<0.001)$ and dyslipidemia $(p<0.001)$ (Table 5).

Patients who were not treated for diabetes were significantly more likely to have diffuse DME in the right eye $(p<0.001)$ and a CMT greater than $300 \mu \mathrm{m}$ in both eyes $(p<0.001$ for each). In addition, the median CMT was significantly greater in untreated than that in treated patients with diabetes in the right eye (376.5 versus $342 \mu \mathrm{m}$, $p=0.002)$ and in the left eye ( 370 versus $329 \mu \mathrm{m}, p<0.001$ ) (Table 5).

\section{Discussion}

The present TURK-DEM study is the first large-scale real-life observational clinical study of patients with newly diagnosed DME in Turkey. In line with the previous observation that DME has a higher prevalence in patients with type 2 diabetes than type 1 diabetes [15], most of our study population had type 2 diabetes. Only $65.5 \%$ of our patients were receiving antidiabetic treatment, and the average HbA1c level was $8.8 \%$. This seems notable given the previously reported association of elevated levels of HbAlc with DME prevalence and deterioration, particularly for patients whose $\mathrm{HbA1c}$ level is above $7 \%$ and who have had diabetes for a long time $[1,16,17]$.

The time from diagnosis of diabetes to occurrence of DME was 10-19 years in half of recruited patients and less than 5 years in only $12.0 \%$ of the patients [18]. This supports the previously reported increase in the prevalence of DME with longer duration of diabetes mellitus $[13,18]$.

In line with the previously reported high prevalence of hypertension in patients with DME [19], 55.1\% of our patients had hypertension and $77.5 \%$ of these hypertensive patients were being treated with antihypertensive agents. Given the increased risk for development and progression of diabetic retinopathy among diabetics with poorly controlled hypertension [20] and the greater risk for development of DME in the presence of hypertension [19], the findings emphasize the importance of controlling hypertension for the prevention and management of DME.

Ophthalmologists and physicians from other disciplines who care for patients with diabetes have an increased awareness of recent advances in DME management, and this may have helped to maximize the impact of these advances [21].
In this cohort, vision problems rather than referral were the most frequent reason for initial admission. Thus, it seems necessary to establish an efficient referral system to enable DME to be diagnosed at an earlier stage.

OCT was the most common method used for diagnosis of DME in our cohort (98.8\%), followed by fundoscopy (92.9\%). SD-OCT was used in most cases, and TD-OCT was only used in $10 \%$ of our patients. This seems notable given that pattern of edema classification on SD-OCT can have a significant impact on treatment decisions and subsequent visual outcome [22-25]. Also, the difference between CMT measurements obtained via TD-OCT and SD-OCT in our study is consistent with previous reports that CMT measured by SD-OCT is $45 \mu \mathrm{m}$ to $58.5 \mu \mathrm{m}$ greater than that measured by TD-OCT [26-28]. Hence, even though the results of these two methods are strongly correlated, our findings support the view that careful consideration should be given to data on CMT measurements that are determined by different OCT methods [26-28]. Regarding CMT values, previous research reported that eyes with greater baseline CMT levels $(>400 \mu \mathrm{m}$ versus $<300-400 \mu \mathrm{m})$ had greater improvement of visual acuity in patients treated with an intravitreal anti-VEGF agent $[29,30]$.

A previous case series indicated that diffuse DME was refractory to macular laser photocoagulation therapy [31]. Thus, the presence of diffuse DME in almost half of the recruited patients is notable given that therapy for diffuse DME remains a major challenge [32].

Moreover, we found that $66.6 \%$ of the patients had baseline CMTs greater than $300 \mu \mathrm{m}$, patients with diffuse DME and with a higher baseline CMT $(>300 \mu \mathrm{m})$ were less likely to have received antidiabetic treatment, and there were significantly higher CMTs in untreated than treated patients with diabetes.

The two major nonsurgical treatments for diabetic retinopathy are retinal laser photocoagulation and pharmacologic approaches, including corticosteroids and VEGF inhibitors [33, 34]. Several biodegradable and nonbiodegradable delivery systems can also help to achieve sustained levels of corticosteroids in the vitreous cavity [35]. Anti-VEGF therapy with pegaptanib sodium, ranibizumab, bevacizumab, or aflibercept can reduce edema and central retinal thickening and improve vision gain or stability [29, 36-39]. Laser photocoagulation is still considered one of the mainstays of treatment for DME along with other alternatives, especially focal DME [17]. Moreover, use of laser therapy after sufficient thinning of the retina by anti-VEGF drugs can promote stabilization of retinal thickness and reduced treatment burden, thereby improving functional outcome and reducing the need for further anti-VEGF injections $[17,40]$. Consistent with these data, laser therapy and anti-VEGF drugs-either alone or in combination-were used to treat most of the cases in our cohort. Thus, the diagnostic work-up and practice patterns among Turkish DME patients seem to be in accordance with recent trends in the management of DME, including the common use of OCT for diagnosis, and the change of standard treatment from laser photocoagulation therapy to intraocular delivery of anti-VEGF agents [21]. 
TABLE 5: Clinical characteristics of patients who did or did not receive antidiabetic treatment.

\begin{tabular}{|c|c|c|c|}
\hline & An & & \\
\hline & No & Yes & $p$ value \\
\hline Type of diabetes, $n(\%)$ & & & \\
\hline Type 1 & $1(3.1)$ & $31(96.9)$ & \\
\hline Type 2 & $195(24.9)$ & $588(74.1)$ & 0.005 \\
\hline Time from onset of diabetes to DME, & & & \\
\hline Less than 5 years & $27(30.3)$ & $62(69.7)$ & \\
\hline $5-9$ years & $73(40.8)$ & $106(59.2)$ & \\
\hline $10-14$ years & $70(29.2)$ & $170(70.8)$ & $<0.001$ \\
\hline $15-19$ years & $17(9.9)$ & $154(90.1)$ & \\
\hline 20 years + & $9(6.6)$ & $127(93.4)$ & \\
\hline Smoking status, $n(\%)$ & & & \\
\hline Smoking & $6(9.1)$ & $60(90.9)$ & \\
\hline Used to smoke & $12(6.2)$ & $183(93.8)$ & $<0.001$ \\
\hline Never smoked & $178(32.1)$ & $376(67.9)$ & \\
\hline Hypertension & & & \\
\hline Not present & $151(38.9)$ & $237(61.1)$ & \\
\hline Present & $45(10.5)$ & $382(89.5)$ & $<0.001$ \\
\hline Dyslipidemia & & & \\
\hline Not present & $171(32.3)$ & $358(67.7)$ & \\
\hline Present & $25(8.7)$ & $261(91.3)$ & $<0.001$ \\
\hline DME type: right eye, $n(\%)$ & & & \\
\hline Diffuse & $121(34.5)$ & $230(65.5)$ & \\
\hline Focal & $56(19.3)$ & $234(80.7)$ & $<0.001$ \\
\hline Mixed & $10(12.5)$ & $70(87.5)$ & \\
\hline DME type: left eye, $n(\%)$ & & & \\
\hline Diffuse & $70(24.8)$ & $212(75.2)$ & \\
\hline Focal & $99(29.1)$ & $241(70.9)$ & 0.269 \\
\hline Mixed & $16(21.3)$ & $59(78.7)$ & \\
\hline CMT: right eye, $n(\%)$ & & & \\
\hline$\leq 300 \mu \mathrm{m}$ & $47(17.4)$ & $222(82.6)$ & \\
\hline$>300 \mu \mathrm{m}$ & $147(28.4)$ & $371(71.6)$ & 0.001 \\
\hline CMT: left eye, $n(\%)$ & & & \\
\hline$\leq 300 \mu \mathrm{m}$ & $42(15.1)$ & $237(84.9)$ & $<0000$ \\
\hline$>300 \mu \mathrm{m}$ & $149(29.9)$ & $349(70.1)$ & $<0.001$ \\
\hline CMT: right eye; median (min-max) & $376.5(160-840)$ & $342(146-999)$ & 0.002 \\
\hline CMT: left eye; median (min-max) & $370(201-780)$ & $329(148-999)$ & $<0.001$ \\
\hline
\end{tabular}

CMT: central macular thickness; DME: diabetic macular edema.

Mann-Whitney $U$, chi-square test, and Fisher's exact test were used with Bonferroni correction.

The major strength of this observational study is that we examined the records of 945 patients with DME from 36 centers throughout Turkey. This means that our findings are probably generalizable to the overall population of Turkey. The main limitation of our study is its observational design, because nonrandomized allocation might have led to bias and confounding. Nevertheless, given the paucity of reliable information on DME in Turkey, our findings provide important baseline data for a large representative sample of DME patients from Turkey and thus constitute a valuable contribution. More importantly, this study is the most comprehensive real-life investigation of newly diagnosed
DME that employed detailed analysis of baseline characteristics and of the different tools and techniques used for diagnosis.

\section{Conclusion}

In conclusion, the present study is the first large-scale real-life registry of newly diagnosed DME patients in Turkey. Most of the patients in our cohort had type 2 diabetes, poor glycemic control, and concomitant systemic hypertension and were diagnosed with diabetes 10-19 years previously. A vision problem, rather than referral from another physician, was 
the most frequent reason for seeking care from an ophthalmologist. SD-OCT and fundoscopy were the most common diagnostic methods, and laser therapy and anti-VEGF therapy were the most common treatments. Two-thirds of patients had baseline CMT values greater than $300 \mu \mathrm{m}$, and almost half of the patients had diffuse DME. A baseline CMT greater than $300 \mu \mathrm{m}$ and diffuse DME were more common in those not receiving treatment for diabetes. The baseline data provided by the present registry provides a foundation for future studies of DME screening and treatment. It also could be used as a basis for prediction of treatment success and the likelihood of reducing visual impairment due to diabetes based on different patient characteristics.

\section{Competing Interests}

Esat Ulay, M.D., and Gulsah Nomak, M.D., are Bayer Türk employees. Other authors declare that they have no conflict of interest.

\section{Acknowledgments}

This study was supported by Bayer Türk. The sponsor or funding organization participated in the design of the study, conducting the study, data collection, data management, data analysis, interpretation of the data, preparation, review, and approval of the manuscript. The authors would like to thank Dr. Cagla Ayhan, M.D., and Professor Sule Oktay, M.D., Ph.D., from KAPPA Consultancy Training Research Ltd. (Istanbul, Turkey) who provided editorial support funded by Bayer Türk. TURK-DEM Study Group (by center name in descending order of number of patients enrolled) is comprised of the following: (1) Assoc. Prof. Banu Ozturk M.D.; Selcuk University Faculty of Medicine, Konya: (2) Assoc. Prof. Defne Kalayci, M.D., Mehmet Onen, M.D., Assoc. Prof. Mehmet Numan Alp, M.D.; Ankara Numune Traning and Research Hospital, Ankara: (3) Prof. Haluk Esgin, M.D.; Trakya University Faculty of Medicine, Edirne: (4) Prof. Ayse Oner, M.D., Neslihan Sinim, M.D.; Erciyes University Faculty of Medicine, Kayseri: (5) Prof. Ihsan Caca, M.D., Muhammed Sahin, M.D.; Dicle University Faculty of Medicine, Diyarbakir: (6) Assoc. Prof. Hurkan Kerimoglu, M.D., Prof. Kemal Gunduz, M.D., Gunhal Satirtav, M.D., Emine Tinkir M.D.; Necmettin Erbakan University Meram Faculty of Medicine, Konya: (7) Prof. Faruk Ozturk, M.D.; Ulucanlar Eye Training and Research Hospital, Ankara: (8) Assoc. Prof. Hidayet Erdol, M.D.; Karadeniz Teknik University Faculty of Medicine, Trabzon: (9) Prof. Umit Inan, M.D.; Afyon Kocatepe University Faculty of Medicine, Afyon: (10) Assoc. Prof. Feyza Onder, M.D., Dr. Melih Ustaoglu, M.D.; Haseki Traning and Research Hospital, Istanbul: (11) Prof. Cemil Apaydın, M.D., M. Erkan Dogan, M.D.; Akdeniz University Faculty of Medicine, Antalya: (12) Assoc. Prof. Nazife Sefi Yurdakul, M.D., Emine Deniz Egrilmez, M.D.; Izmir Ataturk Training and Research Hospital, Izmir: (13) Prof. Sengul Ozdek, M.D., Prof. Berati Hasanreisoglu, M.D., Prof. Gokhan Gurelik, M.D.; Gazi University Faculty of Medicine, Ankara: (14) Prof. Ali Osman Saatci, M.D., Prof. Ferit Hakan Oner,
M.D.; Dokuz Eylul University Faculty of Medicine, Izmir: (15) Prof. Ibrahim Erbagci, M.D., Erol Coskun, M.D.; Gaziantep University Sahinbey Training and Research Hospital, Gaziantep: (16) Prof. Berkant Kaderli, M.D., Prof. Ahmet Ali Yucel, M.D., Assoc. Prof. Ozgur Yalcinbayir, M.D., Sertac Argun Kivanc, M.D.; Uludağ University Faculty of Medicine, Bursa: (17) Prof. Jale Mentes, M.D., Prof. Filiz Afrashi, M.D., Zafer Oztas, M.D.; Ege University Faculty of Medicine, Izmir: (18) Prof. Ozlem Sahin, M.D, Assoc. Prof. Semra Akkaya Turhan, M.D.; Marmara University Faculty of Medicine, Istanbul: (19) Bora Yuksel, M.D.; Izmir Bozyaka Training and Research Hospital, Izmir: (20) Prof. Bora Eldem, M.D., Prof. Sibel Kadayifcilar, M.D.; Hacettepe University Faculty of Medicine, Ankara: (21) Assoc. Prof. Nurullah Cagil, M.D., Dr. Yasin Toklu, M.D., Dr. Mucella Arikan Yorgun, M.D.; Yildirim Beyazit University Faculty of Medicine Ataturk Traning and Research Hospital, Ankara: (22) Assoc. Prof. Nurten Unlu, M.D., Dr. Guney Guner, M.D.; Ankara Traning and Research Hospital, Ankara: (23) Prof. Emin Ozmert, M.D., Prof. Figen Sermet, M.D., Assistant Prof. Sibel Demirel, M.D.; Ankara University Faculty of Medicine, Ankara: (24) Prof. Ayse Nihal Demircan, M.D., Selcuk Sizmaz, M.D., Ebru Esen, M.D.; Cukurova University Faculty of Medicine, Adana: (25) Assoc. Prof. Murat Sonmez, M.D; Gulhane Military Medical Academiy Haydarpasa Training and Research Hospital, Istanbul: (26) Prof. Gursel Yllmaz, M.D., Assoc. Prof. Imran Akkoyun, M.D., Ali Kucukoduk, M.D.; Ankara Baskent University Hospital, Ankara: (27) Prof. Sema Oruc Dundar, M.D., Harun Cakmak, M.D.; Adnan Menderes University Training and Research Hospital, Aydin: (28) Assoc. Prof. Levent Karabas, M.D., Ozgur Kara, M.D.; Kocaeli University Faculty of Medicine, Kocaeli: (29) Prof. Ibrahim Kocer, M.D.; Ataturk University Yakutiye Training and Research Hospital, Erzurum: (30) Prof. Yüksel Sullu, M.D., Tuba Cetinkaya, M.D.; Ondokuz Mayis University Faculty of Medicine, Samsun: (31) Prof. Nazmiye Erol, M.D., Mustafa Deger Bilgec, M.D.; Eskisehir Osmangazi University Faculty of Medicine, Eskisehir: (32) Prof. Ali Hakan Durukan, M.D., Dr. Soner Guven, M.D.; Ankara Gulhane Military Medical Academy, Ankara: (33) Assist. Prof. Rifat Rasier, M.D., Dr. Onur Temizsoylu, M.D., Dr. Nazlı Gul Yalcin, M.D.; Bilim University Florence Nightingale Hospital, Istanbul: (34) Prof. Nur Kir, M.D., Zafer Cebeci, M.D.; Istanbul University Istanbul Faculty of Medicine, Istanbul: (35) Prof. Sema Arvas, M.D., Ahmet Sarici, M.D.; Istanbul University Cerrahpasa Faculty of Medicine, Istanbul: (36) Assoc. Prof. Ufuk Adiguzel, M.D.; Mersin University Faculty of Medicine, Mersin.

\section{References}

[1] R. Varma, N. M. Bressler, Q. V. Doan et al., "Prevalence of and risk factors for diabetic macular edema in the United States," JAMA Ophthalmology, vol. 132, no. 11, pp. 1334-1340, 2014.

[2] J. Bali and R. T. Bali, "Pathological ocular angiogenesis in diabetes: a perspective of emerging paradigms and current evidence," Journal of Clinical Ophthalmology and Research, vol. 1, no. 1, pp. 3-10, 2013. 
[3] S. Wild, G. Roglic, A. Green, R. Sicree, and H. King, "Global prevalence of diabetes: estimates for the year 2000 and projections for 2030," Diabetes Care, vol. 27, no. 5, pp. 1047-1053, 2004.

[4] J. E. Shaw, R. A. Sicree, and P. Z. Zimmet, "Global estimates of the prevalence of diabetes for 2010 and 2030," Diabetes Research and Clinical Practice, vol. 87, no. 1, pp. 4-14, 2010.

[5] J. Studnicka, "The diabetic macular edema - new possibilities of the treatment," Ceská a Slovenská Oftalmologie, vol. 68, no. 2, pp. 61-63, 2012.

[6] R. Klein, B. E. Klein, S. E. Moss, and K. J. Cruickshanks, “The Wisconsin epidemiologic study of diabetic retinopathy. XV. The long-term incidence of macular edema," Ophthalmology, vol. 102, no. 1, pp. 7-16, 1995.

[7] R. Klein, M. D. Knudtson, K. E. Lee, R. Gangnon, and B. E. Klein, "The Wisconsin epidemiologic study of diabetic retinopathy: XXII the twenty-five-year progression of retinopathy in persons with type 1 diabetes," Ophthalmology, vol. 115, no. 11, pp. 1859-1868, 2008.

[8] J. Zhang, J. Ma, N. Zhou, B. Zhang, and J. An, "Insulin use and risk of diabetic macular edema in diabetes mellitus: a systemic review and meta-analysis of observational studies," Medical Science Monitor, vol. 21, pp. 929-936, 2015.

[9] P. Romero-Aroca, J. Reyes-Torres, M. Baget-Bernaldiz, and C. Blasco-Suñe, "Laser treatment for diabetic macular edema in the 21st century," Current Diabetes Reviews, vol. 10, no. 2, pp. 100-112, 2014.

[10] J. A. Ford, A. Elders, D. Shyangdan, P. Royle, and N. Waugh, "The relative clinical effectiveness of ranibizumab and bevacizumab in diabetic macular oedema: an indirect comparison in a systematic review," British Medical Journal, vol. 345, article e5182, 2012.

[11] P. Romero-Aroca, "Is laser photocoagulation treatment currently useful in diabetic macular edema?" Medical Hypothesis, Discovery And Innovation in Ophthalmology, vol. 4, no. 1, pp. 5-8, 2015.

[12] X. D. Liu, X. D. Zhou, Z. Wang, and H. J. Shen, “Comparison of intravitreal bevacizumab with macular photocoagulation for treatment of diabetic macular edema: a systemic review and meta-analysis," International Journal of Ophthalmology, vol. 7, no. 6, pp. 1048-1055, 2014.

[13] A. Tas, M. Z. Bayraktar, U. Erdem, G. Sobaci, and M. Ucar, "Prevalence and risk factors for diabetic retinopathy in Turkey," Gulhane Medical Journal, vol. 47, no. 3, pp. 164-174, 2005, http://www.scopemed.org/?mno=5224Prevalence.

[14] S. Saturni, F. Bellini, F. Braido et al., "Randomized controlled trials and real life studies. Approaches and methodologies: a clinical point of view," Pulmonary Pharmacology and Therapeutics, vol. 27, no. 2, pp. 129-138, 2014.

[15] P. Romero-Aroca, J. Fernández-Balart, M. Baget-Bernaldiz et al., "Changes in the diabetic retinopathy epidemiology after 14 years in a population of type 1 and 2 diabetic patients after the new diabetes mellitus diagnosis criteria and a more strict control of the patients," Journal of Diabetes and its Complications, vol. 23, no. 4, pp. 229-238, 2009.

[16] T. M. Diep and I. Tsui, "Risk factors associated with diabetic macular edema," Diabetes Research and Clinical Practice, vol. 100, no. 3, pp. 298-305, 2013.

[17] C. Mathew, A. Yunirakasiwi, and S. Sanjay, "Updates in the management of diabetic macular edema," Journal of Diabetes Research, vol. 2015, Article ID 794036, 8 pages, 2015.
[18] L. P. Aiello, T. W. Gardner, G. L. King et al., "Diabetic retinopathy," Diabetes Care, vol. 21, no. 1, pp. 143-156, 1998.

[19] J. M. Lopes de Faria, A. E. Jalkh, C. L. Trempe, and J. W. McMeel, "Diabetic macular edema: risk factors and concomitants," Acta Ophthalmologica Scandinavica, vol. 77, no. 2, pp. 170-175, 1999.

[20] L. P. Aiello, M. T. Cahill, and J. S. Wong, "Systemic considerations in the management of diabetic retinopathy," American Journal of Ophthalmology, vol. 132, no. 5, pp. 760-776, 2001.

[21] S. J. Song and T. Y. Wong, "Current concepts in diabetic retinopathy," Diabetes and Metabolism Journal, vol. 38, no. 6, pp. 416-425, 2014.

[22] M. I. Roh, J. H. Kim, and O. W. Kwon, "Features of optical coherence tomography are predictive of visual outcomes after intravitreal bevacizumab injection for diabetic macular edema," Ophthalmologica, vol. 224, no. 6, pp. 374-380, 2010.

[23] C. Framme, P. Schweizer, M. Imesch, S. Wolf, and U. WolfSchnurrbusch, "Behavior of SD-OCT-detected hyperreflective foci in the retina of anti-VEGF-treated patients with diabetic macular edema," Investigative Ophthalmology and Visual Science, vol. 53, no. 9, pp. 5814-5818, 2012.

[24] M. Shimura, K. Yasuda, M. Yasuda, and T. Nakazawa, "Visual outcome after intravitreal bevacizumab depends on the optical coherence tomographic patterns of patients with diffuse diabetic macular edema," Retina, vol. 33, no. 4, pp. 740-747, 2013.

[25] B. Mushtaq, N. J. Crosby, A. T. Dimopoulos et al., "Effect of initial retinal thickness on outcome of intravitreal bevacizumab therapy for diabetic macular edema," Clinical Ophthalmology, vol. 8, pp. 807-812, 2014.

[26] M. Kakinoki, T. Miyake, O. Sawada, T. Sawada, H. Kawamura, and M. Ohji, "Comparison of macular thickness in diabetic macular edema using spectral-domain optical coherence tomography and time-domain optical coherence tomography," Journal of Ophthalmology, vol. 2012, Article ID 959721, 5 pages, 2012.

[27] J. Lammer, C. Scholda, C. Prünte, T. Benesch, U. SchmidtErfurth, and M. Bolz, "Retinal thickness and volume measurements in diabetic macular edema: a comparison of four optical coherence tomography systems," Retina, vol. 31, no. 1, pp. 48-55, 2011.

[28] F. Forooghian, C. Cukras, C. B. Meyerle, E. Y. Chew, and W. T. Wong, "Evaluation of time domain and spectral domain optical coherence tomography in the measurement of diabetic macular edema," Investigative Ophthalmology and Visual Science, vol. 49, no. 10, pp. 4290-4296, 2008.

[29] P. Mitchell, F. Bandello, U. Schmidt-Erfurth et al., "The RESTORE study: ranibizumab monotherapy or combined with laser versus laser monotherapy for diabetic macular edema," Ophthalmology, vol. 118, no. 4, pp. 615-625, 2011.

[30] Diabetic Retinopathy Clinical Research Network, M. J. Elman, L. P. Aiello et al., "Randomized trial evaluating ranibizumab plus prompt or deferred laser or triamcinolone plus prompt laser for diabetic macular edema," Ophthalmology, vol. 117, no. 6, pp. 1064-1077, 2010.

[31] D. J. Browning, M. M. Altaweel, N. M. Bressler, S. B. Bressler, I. U. Scott, and Diabetic Retinopathy Clinical Research Network, "Diabetic macular edema: what is focal and what is diffuse?" American Journal of Ophthalmology, vol. 146, no. 5, pp. 649-655, 2008. 
[32] A. Ophir, R. Hanna, and M. R. Martinez, "Importance of 3-D image reconstruction of spectral-domain OCT on outcome of grid laser photocoagulation for diffuse diabetic macular edema," International Journal of Ophthalmology, vol. 6, no. 6, pp. 836-843, 2013.

[33] M. S. Blumenkranz, "Optimal current and future treatments for diabetic macular oedema," Eye, vol. 24, no. 3, pp. 428-434, 2010.

[34] Early Treatment Diabetic Retinopathy Study research group, "Photocoagulation for diabetic macular edema. Early treatment diabetic retinopathy study report number 1," Archives of Ophthalmology, vol. 103, no. 12, pp. 1796-1806, 1985.

[35] A. J. Augustin, "Upcoming therapeutic advances in diabetic macular edema: an intravitreal dexamethasone drug delivery system," Expert Opinion on Drug Delivery, vol. 8, no. 2, pp. 271-279, 2011.

[36] P. Massin, F. Bandello, J. G. Garweg et al., "Safety and efficacy of ranibizumab in diabetic macular edema (RESOLVE study): a 12-month, randomized, controlled, double-masked, multicenter phase II study," Diabetes Care, vol. 33, no. 11, pp. 2399-2405, 2010.

[37] M. Michaelides, A. Kaines, R. D. Hamilton et al., “A prospective randomized trial of intravitreal bevacizumab or laser therapy in the management of diabetic macular edema (BOLT study) 12-month data: report 2," Ophthalmology, vol. 117, no. 6, pp. 1078-1086, 2010.

[38] D. V. Do, U. Schmidt-Erfurth, V. H. Gonzalez et al., “The DA VINCI study: phase 2 primary results of VEGF trap-eye in patients with diabetic macular edema," Ophthalmology, vol. 118, no. 9, pp. 1819-1826, 2011.

[39] Q. D. Nguyen, D. M. Brown, D. M. Marcus et al., "Ranibizumab for diabetic macular edema: results from 2 phase III randomized trials: RISE and RIDE," Ophthalmology, vol. 119, no. 4, pp. 789-801, 2012.

[40] G. Barteselli, I. Kozak, S. El-Emam, J. Chhablani, M. A. Cortes, and W. R. Freeman, "12-month results of the standardised combination therapy for diabetic macular oedema: intravitreal bevacizumab and navigated retinal photocoagulation," The British Journal of Ophthalmology, vol. 98, no. 8, pp. 1036-1041, 2014. 


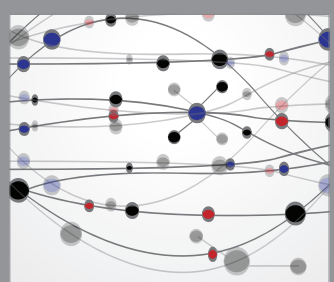

The Scientific World Journal
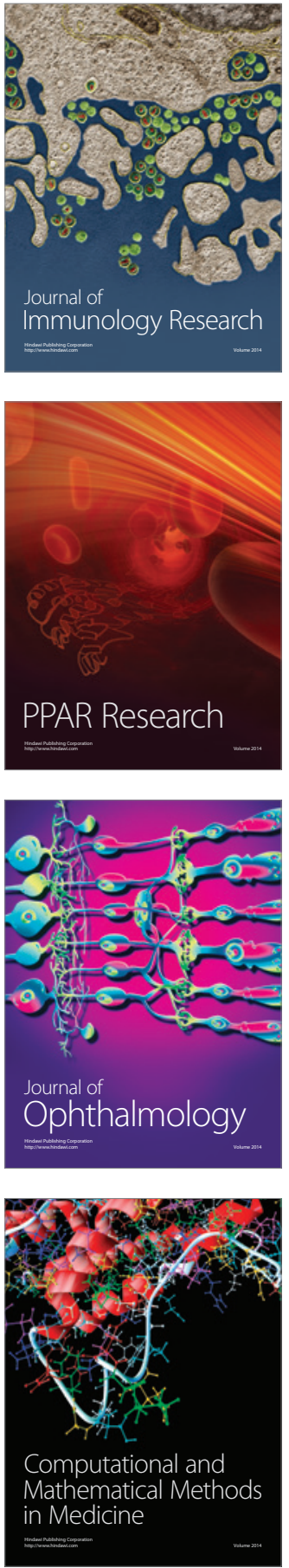

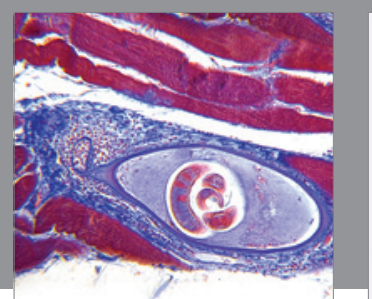

Gastroenterology Research and Practice
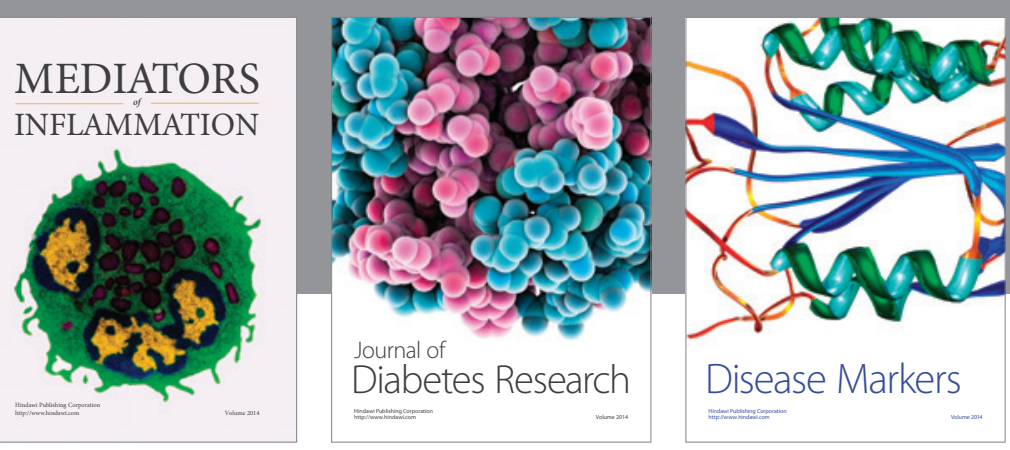

Disease Markers

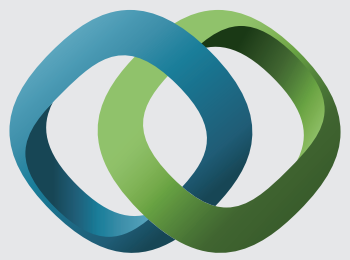

\section{Hindawi}

Submit your manuscripts at

https://www.hindawi.com
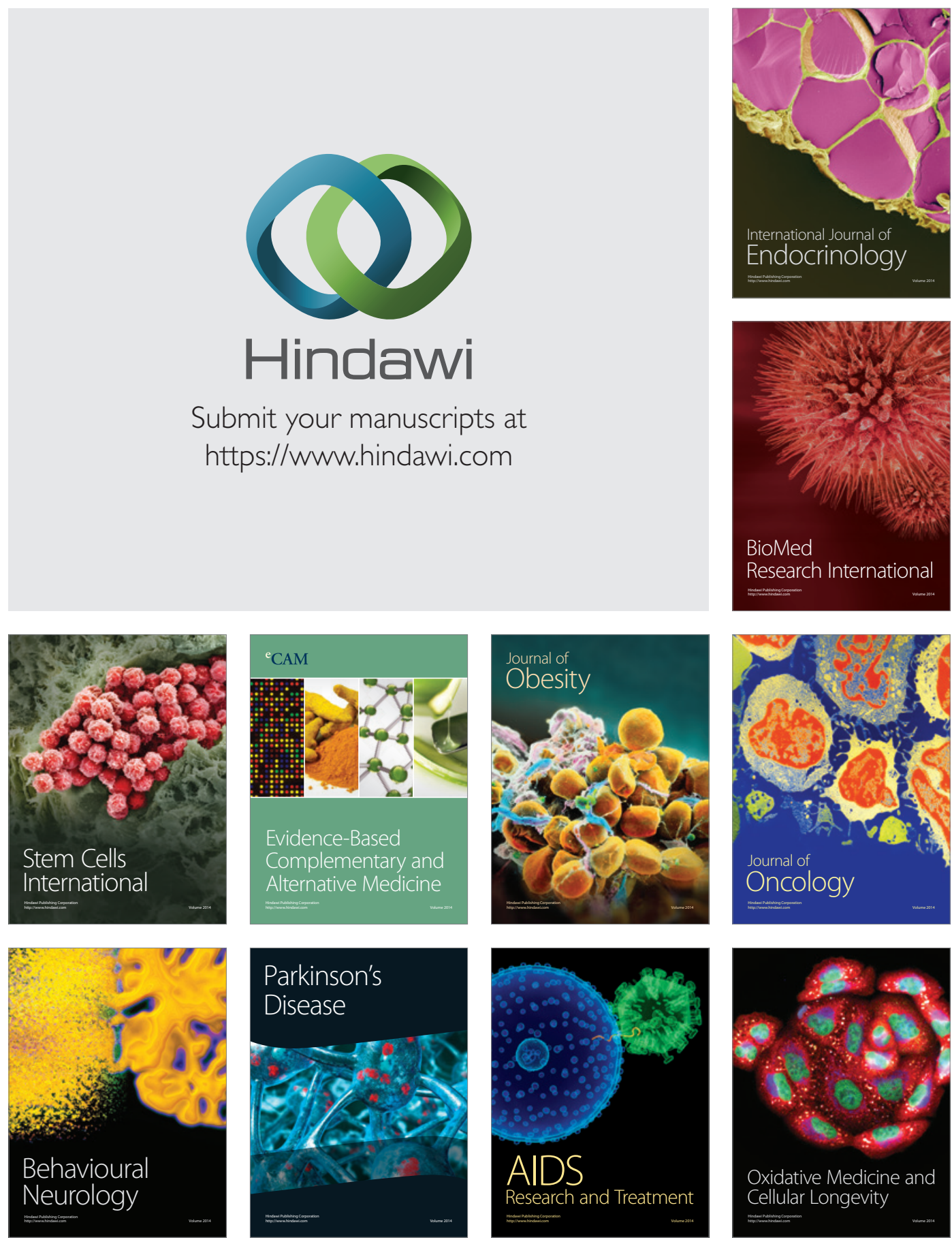